\title{
Temperature Gradient Control of the Solid Oxide Fuel Cell under Variable Load
}

\author{
Haibo Huo,* Kui Xu, Lixiang Cui, Hao Zhang, Jingxiang Xu, and Xinghong Kuang* \\ Cite This: ACS Omega 2021, 6, 27610-27619 \\ Read Online
}

ACCESS |

Lلll Metrics \& More

Article Recommendations

Supporting Information

ABSTRACT: Nowadays, the temperature gradient is considered as one of the most important parameters which impact the performance of the solid oxide fuel cell (SOFC). In this paper, a control strategy based on an input-output feedback linearization technology is derived for controlling the maximum temperature gradient within the anode fuel flow channel at the desired value. For the controller design, the temperature dynamic model is proposed and simplified to a controloriented multi-input and multioutput nonlinear dynamic model. Then, this paper presents an input-output feedback linearization controller to realize the control objective by adjusting the cathode input air flow. Finally, the simulation results are

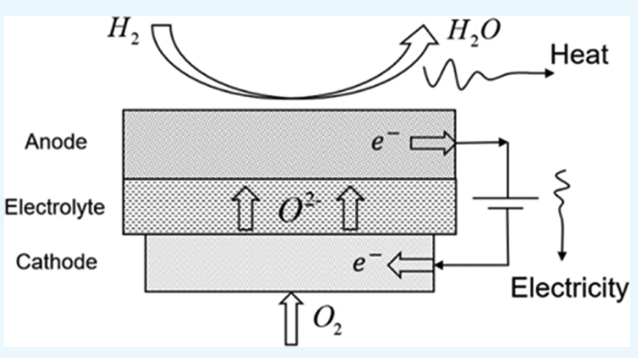
given to demonstrate the accuracy of the proposed model in reflecting the temperature dynamic characteristics. Moreover, the compound controller is added for simulation as a comparison, which shows that the proposed controller is equipped with better effectiveness and efficiency in the presence of external disturbances.

\section{INTRODUCTION}

The solid oxide fuel cell (SOFC) is an energy conversion device which directly converts chemical energy into electrical energy through an electrochemical reaction, and the chemical energy is stored in gas or gas fuel. This energy conversion jumps over the process of converting heat into mechanical energy, which brings the SOFC system not restricted by the Carnot cycle and has high energy conversion efficiency. ${ }^{1}$ Besides, an SOFC also has the advantages of low or zero emissions, high reliability, and no movement mechanism, making it widely usable in many fields.

The SOFC works in a complex high-temperature (600$1000{ }^{\circ} \mathrm{C}$ ) environment; ${ }^{2}$ system nonlinearity, fuel shortage, external interference, and inaccuracy of some variables often cause a few serious problems. The temperature gradient is a key parameter of the SOFC. An excessively high temperature gradient will lead to greater thermal stress in the system, which will cause the fuel cell to deform or even crack and shorten the cell life. ${ }^{3}$ Therefore, to ensure the safe operation and prolong life of the SOFC, the temperature gradient needs to be controlled within a reasonable scope $T_{\mathrm{sol}, \mathrm{g}}^{\max } \leq 8 \mathrm{~K} \cdot \mathrm{cm}^{-1}$.

By far, most of the existing controllers are for the terminal voltage or fuel utilization control of the SOFC. Several researchers have designed proportional-integral (PI) controllers for control of load current, voltage, fuel utilization, and maximum temperature of the SOFC, respectively. ${ }^{5-7}$ Besides, Xia et al. ${ }^{8}$ designed a new PID controller based on the Wiener neural network for tracking the voltage performance of the SOFC. Ławryńczuk ${ }^{9}$ designed a nonlinear model predictive controller to achieve satisfying voltage control. Yu et al. ${ }^{10}$ presented a current feedback controller combined with a static synchronous compensation technique to control the voltage.
However, there are only a few research studies on the control strategy of the temperature gradient. Kulikovsky ${ }^{11}$ put forward a simple equation of temperature gradient in the SOFC stack. Zeng et al. ${ }^{12}$ summarized the commonly used thermal management methods for temperature gradient reduction in the SOFC stack. Also, Wu et al. ${ }^{13}$ designed a nonlinear compound controller to control the SOFC temperature gradient. However, the detailed design process of the compound controller was not described and the control precision can also be improved.

Furthermore, most of the mechanism models of the SOFC in the above research studies have fewer coupling elements. They are very useful to analyze the dynamic performance but not suitable for designing control schemes of the complex SOFC system. To develop effective temperature gradient control strategies, a control-oriented nonlinear dynamic model of the SOFC is first proposed in this paper.

Input-output feedback linearization control is well known for its ability to generate a nonlinear control input, which yields a linear relationship between the inputs and the outputs and eventually permits the use of the conventional linear control approach. ${ }^{14}$ This makes the design of control law more flexible. Until now, input-output feedback linearization control has been successfully applied in many fields, such as

Received: March 14, 2021

Accepted: August 18, 2021

Published: October 11, 2021 
the motor, the distributed solar collectors, friction systems, and so forth. ${ }^{15-20}$ However, the concrete study of input-output feedback linearization controller design for temperature gradient control of the SOFC has not been found in prior literature.

To improve durability and prevent potential failures, a nonlinear controller based on the input-output feedback linearization is proposed to control the temperature gradient within the required range in this study. The contributions of this paper are given as follows in brief:

(1) For the controller design, a control-oriented multi-input and multioutput nonlinear dynamic model, which can accurately reflect the temperature dynamic characteristics of the SOFC, is proposed.

(2) An input-output feedback linearization controller is derived for controlling the maximum temperature gradient within the anode fuel flow channel at the desired value by adjusting the cathode input air flow. Furthermore, the better effectiveness and efficiency in the presence of external disturbances of the proposed controller is demonstrated by comparing with the compound controller.

The rest of this article is arranged as follows. In Section 2, the SOFC dynamic mechanism model proposed in refs 21 and 22 is reviewed in brief, and a control-oriented nonlinear temperature gradient dynamic model is proposed. Then, the controller based on input-output feedback linearization is designed in Section 3. It is followed by Section 4, where the temperature simulation result can verify the accuracy of the dynamic model, and the maximum temperature gradient control result is depicted to show the validity of the presented controller. Finally, conclusions are summarized in Section 5.

\section{DYNAMIC MODEL OF THE SOFC}

2.1. Nonlinear Dynamic Mechanism Model. Based on the work reported in refs 21 and 22, the SOFC dynamic mechanism model is reviewed in this section.

In this paper, a coflow planar SOFC stack composed of 30 single cells is studied. Figure 1 describes the basic structure and

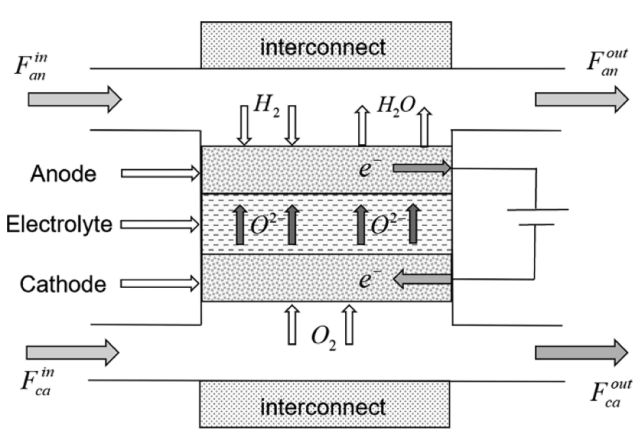

Figure 1. Structure diagram of the single SOFC operation.

operating principle of the single cell. Assuming the reaction processes in the individual cells are the same, the SOFC stack model can be derived from the cell model. To obtain the spatial distribution of temperature and compromise the accuracy and calculation amount, the cell is divided equidistantly into five nodes along the gas flow direction from the inlet to outlet. ${ }^{23,24}$ The finite volume method can realize local conservation in the corresponding unit and is also suitable for dealing with complex range and boundary problems. $^{25}$ Therefore, in this study, the finite volume method is utilized to build the model for the single cell, as shown in Figure 2.

For each mode, the lumped parameter dynamic model includes three parts, that is, mass balance submodel, thermal balance submodel, and electrochemical submodel.

2.1.1. Mass Balance Submodel. Equations 1 and 2 give the mass balance models in the cathode channel, which provide the mole fraction of oxygen in the SOFC. $y_{\mathrm{O}_{2}}{ }^{m}, y_{\mathrm{H}_{2}}{ }^{m}$, and $y_{\mathrm{H}_{2} \mathrm{O}}{ }^{m}$, respectively, represent the mole fractions of oxygen, hydrogen, and water vapor in the $m$-th $(m=1,2,3,4,5)$ node.

$$
\begin{aligned}
\rho_{\mathrm{mol}}^{\mathrm{ca}} V_{\mathrm{gas}}^{\mathrm{ca}} \frac{\mathrm{d} y_{\mathrm{O}_{2}}{ }^{m}}{\mathrm{~d} t}= & y_{\mathrm{O}_{2}}^{\mathrm{in}} F_{\mathrm{ca}}^{\mathrm{in}}-y_{\mathrm{O}_{2}}{ }^{m} F_{\mathrm{ca}}^{\mathrm{in}}-y_{\mathrm{O}_{2}}{ }^{m}\left(-\sum_{j=1}^{m} r_{\mathrm{O}_{2}}{ }^{j}(I)\right) \\
& -r_{\mathrm{O}_{2}}{ }^{m}(I) \\
\rho_{\mathrm{mol}}^{\mathrm{ca}} V_{\mathrm{gas}}^{\mathrm{ca}} \frac{\mathrm{d} y_{\mathrm{O}_{2}}{ }^{m}}{\mathrm{~d} t}= & y_{\mathrm{O}_{2}}{ }^{m-1} F_{\mathrm{ca}}^{\mathrm{in}}+y_{\mathrm{O}_{2}}{ }^{m-1}\left(-\sum_{j=1}^{m-1} r_{\mathrm{O}_{2}}{ }^{j}(I)\right) \\
& -y_{\mathrm{O}_{2}}{ }^{m} F_{\mathrm{ca}}^{\mathrm{in}}-y_{\mathrm{O}_{2}}{ }^{m}\left(-\sum_{j=1}^{m} r_{\mathrm{O}_{2}}{ }^{j}(I)\right)-r_{\mathrm{O}_{2}}{ }^{m}(I)
\end{aligned}
$$

where, $m=1$ for eq 1 and $m=2,3,4,5$ for eq $2, \rho_{\text {mol }}^{\mathrm{ca}}$ and $V_{\mathrm{gas}}^{\mathrm{ca}}$, respectively, represent the molar density and volume in the cathode channel, $r_{\mathrm{O}_{2}}{ }^{j}(I)$ is regarded as the reaction rate of oxygen, $F_{c a}^{\text {in }}$ means the cathode input air flow, and the anode input fuel flow $F_{\mathrm{an}}^{\mathrm{in}}$ is described as follows

$$
F_{\mathrm{an}}^{\mathrm{in}}=\frac{I N}{2 F u_{\mathrm{f}}}
$$

where $I$ is the stack current, $N$ represents the number of cells in the stack, $u_{\mathrm{f}}$ means the fuel utilization, and $F$ denotes the Faraday constant.

Similarly, the mass balance submodels of hydrogen and water vapor in the anode fuel channel are given as follows

$$
\begin{aligned}
& \rho_{\mathrm{mol}}^{\text {an }} V_{\mathrm{gas}}^{\text {an }} \frac{\mathrm{d} r_{\mathrm{H}_{2}}{ }^{m}}{\mathrm{~d} t}=y_{\mathrm{H}_{2}}^{\text {in }} F_{\mathrm{an}}^{\text {in }}-y_{\mathrm{H}_{2}}{ }^{m} F_{\mathrm{an}}^{\mathrm{in}}-y_{\mathrm{H}_{2}}{ }^{m} \\
& \left(-\sum_{j=1}^{m}{r_{\mathrm{H}_{2}}}^{j}(I)+\sum_{j=1}^{m}{r_{\mathrm{H}_{2} \mathrm{O}}}^{j}(I)\right)-r_{\mathrm{H}_{2}}^{m}(I) \\
& \rho_{\mathrm{mol}}^{\mathrm{an}} V_{\mathrm{gas}}^{\mathrm{an}} \frac{\mathrm{d} y_{\mathrm{H}_{2}}{ }^{m}}{\mathrm{~d} t}=y_{\mathrm{H}_{2}}{ }^{m-1} F_{\mathrm{an}}^{\mathrm{in}}+y_{\mathrm{H}_{2}}{ }^{m-1}\left(-\sum_{j=1}^{m-1} r_{\mathrm{H}_{2}}{ }^{j}(I)\right. \\
& \left.+\sum_{j=1}^{m-1} r_{\mathrm{H}_{2} \mathrm{O}}{ }^{j}(I)\right)-y_{\mathrm{H}_{2}}^{m} F_{\mathrm{an}}^{\mathrm{in}} \\
& -y_{\mathrm{H}_{2}}{ }^{m}\left(-\sum_{j=1}^{m} r_{\mathrm{H}_{2}}^{j}(I)+\sum_{j=1}^{m} r_{\mathrm{H}_{2} \mathrm{O}}{ }^{j}(I)\right) \\
& -r_{\mathrm{H}_{2}}^{m}(I)
\end{aligned}
$$




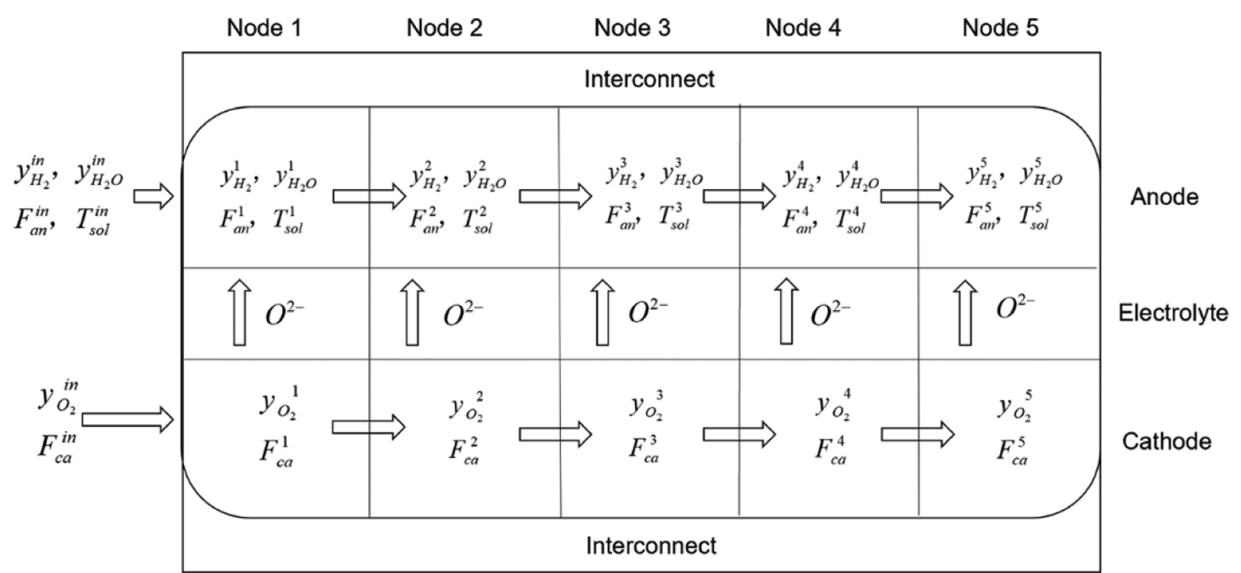

Figure 2. Finite volume scheme on the SOFC.

$$
\begin{aligned}
& \rho_{\mathrm{mol}}^{\text {an }} V_{\mathrm{gas}}^{\mathrm{an}} \frac{\mathrm{d} y_{\mathrm{H}_{2} \mathrm{O}}{ }^{m}}{\mathrm{~d} t}=y_{\mathrm{H}_{2} \mathrm{O}}^{\text {in }} F_{\text {an }}^{\text {in }}-y_{\mathrm{H}_{2} \mathrm{O}}{ }^{m} F_{\text {an }}^{\text {in }} \\
& -y_{\mathrm{H}_{2} \mathrm{O}} m\left(-\sum_{j=1}^{m} r_{\mathrm{H}_{2}}^{j}(I)+\sum_{j=1}^{m} r_{\mathrm{H}_{2} \mathrm{O}}{ }^{j}(I)\right) \\
& +r_{\mathrm{H}_{2}}{ }^{m}(I) \\
& \rho_{\mathrm{mol}}^{\mathrm{an}} V_{\mathrm{gas}}^{\mathrm{an}} \frac{\mathrm{d} y_{\mathrm{H}_{2} \mathrm{O}}{ }^{m}}{\mathrm{~d} t}=y_{\mathrm{H}_{2} \mathrm{O}}{ }^{m-1} F_{\mathrm{an}}^{\mathrm{in}}+y_{\mathrm{H}_{2} \mathrm{O}}{ }^{m-1}\left(-\sum_{j=1}^{m-1} r_{\mathrm{H}_{2}}{ }^{j}(I)\right. \\
& \left.+\sum_{j=1}^{m-1} r_{\mathrm{H}_{2} \mathrm{O}}^{j}(I)\right)-y_{\mathrm{H}_{2} \mathrm{O}}^{m} F_{\mathrm{an}}^{\mathrm{in}} \\
& -y_{\mathrm{H}_{2} \mathrm{O}}^{m}\left(-\sum_{j=1}^{m} r_{\mathrm{H}_{2}}^{j}(I)+\sum_{j=1}^{m} r_{\mathrm{H}_{2} \mathrm{O}}{ }^{j}(I)\right) \\
& +r_{\mathrm{H}_{2} \mathrm{O}}{ }^{m}(I)
\end{aligned}
$$

where $m=1$ for eqs 4 and 6 , and $m=2,3,4,5$ for eqs 5 and 7 , $\rho_{\text {mol }}^{\text {an }}$ represents the anode molar density, $V_{\text {gas }}^{\text {an }}$ is the anode gas channel volume, and $r_{\mathrm{H}_{2}}{ }^{j}(I)$ and $r_{\mathrm{H}_{2} \mathrm{O}}{ }^{j}(I)$ are the reaction rates of hydrogen and water vapor, respectively.

In the above formulas, the reaction rates are

$$
\begin{aligned}
& r_{\mathrm{H}_{2}}{ }^{j}(I)=\frac{\nu_{\mathrm{H}_{2}} I}{2 F} \\
& r_{\mathrm{H}_{2} \mathrm{O}}{ }^{j}(I)=\frac{\nu_{\mathrm{H}_{2} \mathrm{O}} I}{2 F} \\
& r_{\mathrm{O}_{2}}{ }^{j}(I)=\frac{\nu_{\mathrm{O}_{2}} I}{2 F}
\end{aligned}
$$

where $v$ represents the stoichiometric coefficient.

2.1.2. Thermal Balance Submodel. The temperature of the solid structure is one of the most important operating variables that affects the performance of the SOFC because the heattransfer coefficients of the solid structure, namely, of the PEN and the interconnector, are much smaller than those of the gases. Thus, the PEN and interconnector temperatures are assumed to be equal. Since the anode fuel flow rate $F_{\text {an }}$ in $=I N /$ $2 F u_{\mathrm{f}}$ (about $2 \times 10^{-4} \mathrm{~mol} \mathrm{~s}^{-1}$ ) is much smaller than the cathode air flow rate $\left(2.742 \times 10^{-3} \mathrm{~mol} \mathrm{~s}^{-1}\right){ }^{21}$ the fuel has enough time for chemical reaction and heat exchange with the solid structure. In this paper, we assume that the anode fuel temperature equals that of the solid structure in each node. The thermal balance equations for the solid structure are described as

$$
\begin{aligned}
& \rho_{s} V_{\text {sol }} c_{p}^{{ }^{s}} \frac{\mathrm{d} T_{\text {sol }}{ }^{m}}{\mathrm{~d} t}=c_{p}^{\mathrm{an}} T^{\mathrm{in}} F_{\mathrm{an}}^{\mathrm{in}}+c_{p}^{\mathrm{ca}} T^{\mathrm{in}} F_{\mathrm{ca}}^{\mathrm{in}}-c_{p}^{\mathrm{an}} T_{\text {sol }}{ }^{m} F_{\text {an }}^{\mathrm{in}}
\end{aligned}
$$

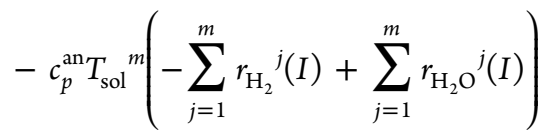

$$
\begin{aligned}
& -c_{p}^{\mathrm{ca}} T_{\mathrm{sol}}{ }^{m} F_{\mathrm{ca}}^{\mathrm{in}}-c_{p}^{\mathrm{ca}} T_{\mathrm{sol}}{ }^{m}\left(-\sum_{j=1}^{m} r_{\mathrm{O}_{2}}^{j}(I)\right) \\
& +\frac{241830 I}{2 F}-I U_{\text {cell }}^{m} \\
& \rho_{s} V_{\text {sol }} c_{p}^{s} \frac{\mathrm{d} T_{\text {sol }}{ }^{m}}{\mathrm{~d} t}=c_{p}^{\mathrm{an}} T_{\mathrm{sol}}{ }^{m-1} F_{\mathrm{an}}^{\mathrm{in}}+c_{p}^{\mathrm{an}} T_{\mathrm{sol}}{ }^{m-1}\left(-\sum_{j=1}^{m-1} r_{\mathrm{H}_{2}}{ }^{j}(I)\right. \\
& \left.+\sum_{j=1}^{m-1} r_{\mathrm{H}_{2} \mathrm{O}}{ }^{j}(I)\right)+c_{p}^{\mathrm{ca}} T_{\text {sol }}{ }^{m-1} F_{\mathrm{ca}}^{\text {in }} \\
& +c_{p}^{\mathrm{ca}} T_{\text {sol }}{ }^{m-1}\left(-\sum_{j=1}^{m-1} r_{\mathrm{O}_{2}}{ }^{j}(I)\right)-c_{p}^{\mathrm{an}} T_{\text {sol }}{ }^{m} F_{\mathrm{an}}^{\mathrm{in}} \\
& -c_{p}^{\mathrm{ca}} T_{\mathrm{sol}}{ }^{m} F_{\mathrm{ca}}^{\mathrm{in}}-c_{p}^{\mathrm{an}} T_{\mathrm{sol}}{ }^{m}\left(-\sum_{j=1}^{m} r_{\mathrm{H}_{2}}{ }^{j}(I)\right. \\
& \left.+\sum_{j=1}^{m} r_{\mathrm{H}_{2} \mathrm{O}}{ }^{j}(I)\right)-c_{p}^{\mathrm{ca}} T_{\mathrm{sol}}^{m}\left(-\sum_{j=1}^{m} r_{\mathrm{O}_{2}}^{j}(I)\right) \\
& +\frac{241830 I}{2 F}-I U_{\text {cell }}^{m}
\end{aligned}
$$

where, $m=1$ for eq 11 and $m=2,3,4,5$ for eq $12, V_{\text {sol }}$ is the volume of the solid structure, $c_{p}^{\text {an }}$ and $c_{p}^{\text {ca }}$ mean the specific heat capacity in the anode and the cathode, respectively, $T^{\text {in }}$ represents the anode input fuel temperature, and 241830I/ $2 F$ is the energy density. 
2.1.3. Electrochemical Submodel. Considering the effect of the ohmic losses and the polarization losses, the voltage in each node of the SOFC can be represented by

$$
U_{\text {cell }}{ }^{m}=U_{\mathrm{N}}{ }^{m}-U_{\text {ohm }}{ }^{m}-U_{\text {act }}{ }^{m}-U_{\text {con }}{ }^{m}
$$

where $E_{N}^{m}$ is the open circuit voltage of the $m$-th node, $U_{\mathrm{ohm}}^{m}$, $U_{\mathrm{act}}^{m}$ and $U_{\text {con, }}^{m}$ respectively, represent the ohmic losses, the activation losses, and the concentration losses of the $m$-th node.

$$
\begin{aligned}
E_{N}{ }^{m} & =E_{0}{ }^{m}+\frac{R T_{\text {sol }}^{m}}{2 F} \ln \left(\frac{y_{\mathrm{H}_{2}}{\sqrt[m]{\mathrm{O}_{2}}}^{m}}{y_{\mathrm{H}_{2} \mathrm{O}}{ }^{m}}\right) \\
& =1.2586-0.000252 T_{\mathrm{sol}}^{m}+\frac{R T_{\text {sol }}{ }^{m}}{2 F} \ln \left(\frac{y_{\mathrm{H}_{2}}{\sqrt[m]{\mathrm{O}_{2}}}^{m}}{y_{\mathrm{H}_{2} \mathrm{O}}^{m}}\right) \\
U_{\text {ohm }}{ }^{m} & =I R_{\mathrm{ohm}} \\
U_{\text {act }}{ }^{m} & =\frac{R T_{\text {sol }}{ }^{m}}{2 F} \sin \mathrm{h}^{-1}\left(\frac{0.5 I}{I_{0}}\right) \\
U_{\text {con }}{ }^{m} & =\frac{R T_{\text {sol }}^{m}}{2 F} \ln \left(\frac{I_{\mathrm{L}}}{I_{\mathrm{L}}-I}\right)
\end{aligned}
$$

where $I_{\mathrm{L}}$ and $I_{0}$ denote the limited current and the change current, respectively. $R$ is the universal gas constant, and $1.2586-0.000252 T_{\mathrm{sol}}^{m}$ represents the standard cell potential, which is $E_{0}^{m}$ in eq 14 .

In fact, in a SOFC operation, the flow, thermal, chemical, and electrochemical (EC) processes are intrinsically coupled. Heat generation and absorption by the chemical and EC reactions in turn affect the temperature distribution and gas flow composition.

\section{CONTROL-ORIENTED NONLINEAR TEMPERATURE GRADIENT MODEL}

To design suitable control strategies for temperature gradient control, a control-oriented nonlinear dynamic model needs to be established based on the SOFC thermal balance submodel. For the controller design, the node temperatures are taken as the state variables, namely, $x=\left[x_{1}, x_{2}, x_{3}, x_{4}, x_{5}\right]^{T}=\left[T_{\text {sol }}^{1}, T_{\text {sol }}^{2}\right.$, $\left.T_{\text {sol }}^{3}, \quad T_{\text {sol }}^{4}, T_{\text {sol }}^{5}\right]^{T}$, the output variable is the maximum temperature gradient among the five nodes, that is, $y=T_{\mathrm{sol}, g}^{\max }$ which is within the anode fuel flow channel, the current is regarded as a bounded disturbance, that is, $\Delta j=I$, and the cathode input air flow is chosen as the manipulated variable. According to the temperature dynamics, as shown in eqs 11 and 12 , the nonlinear dynamic model of the SOFC can be built as

$$
\begin{aligned}
& \dot{\boldsymbol{x}}_{5}=\left[\begin{array}{c}
\dot{\boldsymbol{x}}_{1} \\
\dot{\boldsymbol{x}}_{2} \\
\dot{\boldsymbol{x}}_{3} \\
\dot{\boldsymbol{x}}_{4} \\
\dot{\boldsymbol{x}}_{5}
\end{array}\right] \\
& {\left[\begin{array}{l}
a_{12}\left(c_{2} F_{\mathrm{ca}}^{\mathrm{in}}+c_{1} F_{\mathrm{an}}^{\mathrm{in}}\right)\left(x_{0}-x_{1}\right) \\
\quad+\left[c_{2} a_{6} a_{12} x_{1}+a_{12}\left(a_{11}-U_{\text {cell }}^{1}\right)\right] \Delta j
\end{array}\right.} \\
& a_{12}\left(c_{2} F_{\mathrm{ca}}^{\mathrm{in}}+c_{1} F_{\mathrm{an}}^{\mathrm{in}}\right)\left(x_{1}-x_{2}\right) \\
& +\left[c_{2} a_{12}\left(a_{6} x_{1}-a_{7} x_{2}\right)+a_{12}\right. \\
& \left.\left(a_{11}-U_{\text {cell }}^{2}\right)\right] \Delta j \\
& a_{12}\left(c_{2} F_{\mathrm{ca}}^{\mathrm{in}}+c_{1} F_{\mathrm{an}}^{\mathrm{in}}\right)\left(x_{2}-x_{3}\right) \\
& =\left[\begin{array}{l}
+\left[c_{2} a_{12}\left(a_{7} x_{2}-a_{8} x_{3}\right)+a_{12}\right. \\
\left.\left(a_{11}-U_{\text {cell }}^{3}\right)\right] \Delta j
\end{array}\right. \\
& a_{12}\left(c_{2} F_{\mathrm{ca}}^{\mathrm{in}}+c_{1} F_{\mathrm{an}}^{\mathrm{in}}\right)\left(x_{3}-x_{4}\right) \\
& +\left[c_{2} a_{12}\left(a_{8} x_{3}-a_{9} x_{4}\right)+a_{12}\right. \\
& \left.\left(a_{11}-U_{\text {cell }}^{4}\right)\right] \Delta j \\
& a_{12}\left(c_{2} F_{\mathrm{ca}}^{\mathrm{in}}+c_{1} F_{\mathrm{an}}^{\mathrm{in}}\right)\left(x_{4}-x_{5}\right) \\
& +\left[c_{2} a_{12}\left(a_{9} x_{4}-a_{10} x_{5}\right)+a_{12}\right. \\
& \left.\left(a_{11}-U_{\text {cell }}^{5}\right)\right] \Delta j \\
& \boldsymbol{y}=T_{\mathrm{sol}, \mathrm{g}}^{\mathrm{max}}=\max \left[\left(x_{1}-x_{0}\right),\left(x_{2}-x_{1}\right), \quad\left(x_{3}-x_{2}\right),\right. \\
& \left.\left(x_{4}-x_{3}\right),\left(x_{5}-x_{4}\right)\right]
\end{aligned}
$$

where, $x_{0}$ means the initial temperature of the solid structure, which is also the anode input fuel temperature. Furthermore, several notations define the parameters below

$$
\begin{aligned}
& a_{1}=-\sum_{j=1}^{1} r_{\mathrm{H}_{2}}^{j}(I)+\sum_{j=1}^{1} r_{\mathrm{H}_{2} \mathrm{O}}^{j}(I) \\
& a_{2}=-\sum_{j=1}^{2} r_{\mathrm{H}_{2}}^{j}(I)+\sum_{j=1}^{2} r_{\mathrm{H}_{2} \mathrm{O}}^{j}(I) \\
& a_{3}=-\sum_{j=1}^{3} r_{\mathrm{H}_{2}}^{j}(I)+\sum_{j=1}^{3} r_{\mathrm{H}_{2} \mathrm{O}}^{j}(I) \\
& a_{4}=-\sum_{j=1}^{4} r_{\mathrm{H}_{2}}^{j}(I)+\sum_{j=1}^{4} r_{\mathrm{H}_{2} \mathrm{O}}^{j}(I) \\
& a_{5}=-\sum_{j=1}^{5} r_{\mathrm{H}_{2}}{ }^{j}(I)+\sum_{j=1}^{5} r_{\mathrm{H}_{2} \mathrm{O}}{ }^{j}(I) \quad a_{6}=-\frac{1}{2 F} \\
& a_{7}=-\frac{1}{F} \quad a_{8}=-\frac{3}{2 F} \\
& \begin{array}{rlr}
a_{9}=-\frac{2}{F} \quad a_{10}=-\frac{5}{2 F} & a_{11}=\frac{241830}{2 F} \\
a_{12}=\frac{1}{\rho_{s} V_{s} c_{p}^{s}} \quad c_{1}=c_{p}^{\text {an }} & c_{2}=c_{p}^{c a}
\end{array}
\end{aligned}
$$

In this paper, we control the temperature gradient by adjusting the cathode input air flow. To design the inputoutput feedback linearization controller, according to eq 18 , the control-oriented nonlinear temperature gradient model can be derived as 


$$
\begin{aligned}
\dot{\boldsymbol{x}}= & \boldsymbol{f}(\boldsymbol{x})+\boldsymbol{G}(\boldsymbol{x}) \boldsymbol{u}+\mathbf{d}(\boldsymbol{x}, \Delta j) \\
\boldsymbol{y}= & \boldsymbol{h}(\boldsymbol{x})=T_{\mathrm{sol}, \mathrm{g}}^{\max }=\max \left[\left(x_{1}-x_{0}\right),\left(x_{2}-x_{1}\right),\right. \\
& \left.\left(x_{3}-x_{2}\right),\left(x_{4}-x_{3}\right),\left(x_{5}-x_{4}\right)\right]
\end{aligned}
$$

where the control input $\boldsymbol{u}$ is the cathode input air flow, and

$$
\begin{gathered}
\boldsymbol{f}(\boldsymbol{x})=\left[\begin{array}{l}
c_{1} a_{12} F_{\mathrm{an}}^{\mathrm{in}}\left(x_{0}-x_{1}\right) \\
c_{1} a_{12} F_{\mathrm{an}}^{\mathrm{in}}\left(x_{1}-x_{2}\right) \\
c_{1} a_{12} F_{\mathrm{an}}^{\mathrm{in}}\left(x_{2}-x_{3}\right) \\
c_{1} a_{12} F_{\mathrm{an}}^{\mathrm{in}}\left(x_{3}-x_{4}\right) \\
c_{1} a_{12} F_{\mathrm{an}}^{\mathrm{in}}\left(x_{4}-x_{5}\right)
\end{array}\right], \\
\boldsymbol{G}(\boldsymbol{x})=\left[\begin{array}{l}
c_{2} a_{12}\left(x_{0}-x_{1}\right) \\
c_{2} a_{12}\left(x_{1}-x_{2}\right) \\
c_{2} a_{12}\left(x_{2}-x_{3}\right) \\
c_{2} a_{12}\left(x_{3}-x_{4}\right) \\
c_{2} a_{12}\left(x_{4}-x_{5}\right)
\end{array}\right], \\
\boldsymbol{d}\left(\boldsymbol{x}, \Delta_{j}\right)=\hat{\boldsymbol{d}}(\boldsymbol{x}) \Delta j \\
=\left[\begin{array}{l}
c_{2} a_{12} a_{6} x_{1}+a_{12}\left(a_{11}-U_{\text {cell }}^{1}\right) \\
c_{2} a_{12}\left(a_{6} x_{1}-a_{7} x_{2}\right)+a_{12}\left(a_{11}-U_{\text {cell }}{ }^{2}\right) \\
c_{2} a_{12}\left(a_{7} x_{2}-a_{8} x_{3}\right)+a_{12}\left(a_{11}-U_{\text {cell }}{ }^{3}\right) \\
c_{2} a_{12}\left(a_{8} x_{3}-a_{9} x_{4}\right)+a_{12}\left(a_{11}-U_{\text {cell }}{ }^{4}\right) \\
c_{2} a_{12}\left(a_{9} x_{4}-a_{10} x_{5}\right)+a_{12}\left(a_{11}-U_{\text {cell }}^{5}\right)
\end{array}\right] \Delta j
\end{gathered}
$$

\section{TEMPERATURE GRADIENT CONTROL OF THE SOFC}

4.1. Input-Output Feedback Linearization. In recent years, feedback linearization has become a popular nonlinear system control method, which is widely used in the decoupling, output regulation and response tracking of nonlinear systems. Feedback linearization is conveniently classified into categories, that is, input-output feedback linearization and statespace linearization. Input-output feedback linearization technology provides convenience for further design of linearization control algorithm by transforming the nonlinear system model (in whole or part) into a linear system. ${ }^{26,27}$ The standard input and output feedback linearization technology is described as follows.

Consider the following nonlinear dynamic model

$$
\left\{\begin{array}{l}
\dot{x}=f(x)+G(x) u \\
y=H(x)
\end{array}\right.
$$

where $x \in R^{n}$ is the state vector, $\boldsymbol{u} \in \boldsymbol{R}^{m}$ is the control input, $\boldsymbol{y}$ $\in \boldsymbol{R}^{m} \quad$ is the system output, $\boldsymbol{f}(\boldsymbol{x}), \boldsymbol{G}(\boldsymbol{x})=\left[g_{1}(\boldsymbol{x}), \ldots, g_{m}(\boldsymbol{x})\right]$, $\boldsymbol{H}(\boldsymbol{x})=\left[h_{1}(\boldsymbol{x}), \ldots, h_{m}(\boldsymbol{x})\right]^{T}$ and $g_{i}(i=1, \ldots, m)$ are all $n$ dimensions smooth vector fields, and $h_{i}(i=1, \ldots, m)$ is the sufficiently smooth scalar function.

We define the first derivative of the output variable $y$ as follows

$$
\dot{y}_{i}=L_{\mathrm{f}}{ }^{1} h_{i}+\sum_{j=1}^{m}\left(L_{g_{j}}{ }^{1} h_{i}\right) u_{j}
$$

where $L_{\mathrm{f}}^{1} h_{i}=\partial h_{i}(\boldsymbol{x}) / \partial x f(\boldsymbol{x}), L_{\mathrm{gj}}^{1} h_{i}=\partial h_{i}(\boldsymbol{x}) / \partial x g_{i}(\boldsymbol{x})$.

If $L_{\mathrm{g}_{j}}{ }^{1} h_{i} \neq 0$, the first derivative of $y$ is connected to the control law $\boldsymbol{u}$. The control law can be directly derived as $\boldsymbol{u}_{j}=\frac{1}{L_{g_{j}} h_{i}}\left(v-L_{\mathrm{f}}{ }^{1} h_{i}\right),{ }^{28,29}$ where $v$ denotes the derivative of $\boldsymbol{y}$ and can obtain linear relationships between the inputs and outputs. ${ }^{14}$ Supposing that all the $L_{\mathrm{g}_{j}}{ }^{1} h_{i} \equiv 0$, it means that the derivative of $\boldsymbol{y}$ has no relationship with the control law $\boldsymbol{u}$; then, the derivation needs to be continued. Let us assume that $\lambda_{j}$ is the minimum integer and at least one $L_{\mathrm{g}_{j}}\left(L_{\mathrm{f}}{ }^{\lambda_{j}-1} h_{j}\right)$ not to be zero, that is

$$
\begin{aligned}
& y_{j}^{(i)}=L_{f}{ }^{i} h_{j}, \quad i=0,1, \ldots, \lambda_{j}-1 \\
& y_{i}^{\left(\lambda_{j}\right)}=L_{f}{ }^{\lambda_{j}} h_{j}+\sum_{j=1}^{n} L_{g_{j}}\left(L_{f}^{\lambda_{j}-1} h_{j}\right) u_{j}
\end{aligned}
$$

Thus, the control law $\boldsymbol{u}$ is

$$
\boldsymbol{u}_{j}=\frac{1}{L_{g_{j}} L_{f}^{\lambda_{j}-1} h_{j}}\left(v-L_{f}{ }^{\lambda_{j}} h_{j}\right)
$$

4.2. Model Linearization and Controller Design. When a load disturbance causes the current change, the control objective is to exactly track the desired maximum temperature gradient by controlling the cathode input air flow. Applying the input-output feedback linearization technique described in Section 4.1, the first-time derivative of $\boldsymbol{y}$ in eq 19 can be derived as

$$
\begin{aligned}
\dot{y}= & \frac{\partial h(\boldsymbol{x})}{\partial \boldsymbol{x}}[\boldsymbol{f}(\boldsymbol{x})+\boldsymbol{G}(\boldsymbol{x}) \boldsymbol{u}+\hat{\boldsymbol{d}}(\boldsymbol{x}) \Delta j] \\
& =\left\{\begin{array}{c}
L_{f_{1}}{ }^{1} h_{1}+L_{g_{1}}{ }^{1} h_{1} u+L_{\hat{d}_{1}}{ }^{1} h_{1} \Delta j \\
y=x_{1}-x_{0} \\
L_{f_{2}}{ }^{1} h_{2}+L_{g_{2}}{ }^{1} h_{2} u+L_{\hat{d}_{2}}{ }^{1} h_{2} \Delta j \\
y=x_{2}-x_{1} \\
L_{f_{3}}{ }^{1} h_{3}+L_{g_{3}}{ }^{1} h_{3} u+L_{\hat{d}_{3}}{ }^{1} h_{3} \Delta j \\
y=x_{3}-x_{2} \\
L_{f_{4}}{ }^{1} h_{4}+L_{g_{4}}{ }^{1} h_{4} u+L_{\hat{d}_{4}}{ }^{1} h_{4} \Delta j \\
y=x_{4}-x_{3} \\
L_{f_{5}}{ }^{1} h_{5}+L_{g_{5}}{ }^{1} h_{5} u+L_{\hat{d}_{5}}{ }^{1} h_{5} \Delta j \\
y=x_{5}-x_{4}
\end{array}\right.
\end{aligned}
$$

where 


$$
\begin{aligned}
L_{f}{ }^{1} h & =\frac{\partial h(\boldsymbol{x})}{\partial \boldsymbol{x}} \boldsymbol{f}(\boldsymbol{x}) \\
& = \begin{cases}c_{1} a_{12} F_{\mathrm{an}}^{\mathrm{in}}\left(x_{0}-x_{1}\right), & y=x_{1}-x_{0} \\
c_{1} a_{12} F_{\mathrm{an}}^{\mathrm{in}}\left(2 x_{1}-x_{0}-x_{2}\right), & y=x_{2}-x_{1} \\
c_{1} a_{12} F_{\mathrm{an}}^{\mathrm{in}}\left(2 x_{2}-x_{1}-x_{3}\right), & y=x_{3}-x_{2} \\
c_{1} a_{12} F_{\text {an }}^{\mathrm{in}}\left(2 x_{3}-x_{2}-x_{4}\right), & y=x_{4}-x_{3} \\
c_{1} a_{12} F_{\mathrm{an}}^{\mathrm{in}}\left(2 x_{4}-x_{3}-x_{5}\right), & y=x_{5}-x_{4}\end{cases}
\end{aligned}
$$

$$
\begin{aligned}
L_{\mathrm{g}}{ }^{1} h & =\frac{\partial h(\boldsymbol{x})}{\partial \boldsymbol{x}} \boldsymbol{G}(\boldsymbol{x}) \\
\quad= & \begin{array}{ll}
c_{2} a_{12}\left(x_{0}-x_{1}\right), & y=x_{1}-x_{0} \\
c_{2} a_{12}\left(2 x_{1}-x_{0}-x_{2}\right), & y=x_{2}-x_{1} \\
c_{2} a_{12}\left(2 x_{2}-x_{1}-x_{3}\right), & y=x_{3}-x_{2} \\
c_{2} a_{12}\left(2 x_{3}-x_{2}-x_{4}\right), & y=x_{4}-x_{3} \\
c_{2} a_{12}\left(2 x_{4}-x_{3}-x_{5}\right), & y=x_{5}-x_{4}
\end{array}
\end{aligned}
$$

$$
\begin{aligned}
& L_{\hat{d}}^{1} h= \frac{\partial h(\boldsymbol{x})}{\partial \boldsymbol{x}} \hat{\boldsymbol{d}}(\boldsymbol{x}) \\
&= \begin{array}{ll}
c_{2} a_{12} a_{6} x_{1}+a_{12}\left(a_{11}-U_{c e l l}^{1}\right), \\
\quad y=x_{1}-x_{0} \\
-c_{2} a_{12} a_{7} x_{2}+a_{12}\left(U_{\text {cell }}^{1}-U_{\text {cell }}^{2}\right), \\
\quad y=x_{2}-x_{1} \\
\quad+a_{12}\left(U_{\text {cell }}^{2}-U_{\text {cell }}{ }^{3}\right), \\
\quad\left(2 a_{7} x_{2}-a_{6} x_{1}-a_{8} x_{3}\right) \\
c_{2} a_{12}\left(2 a_{8} x_{3}-a_{7} x_{2}-a_{9} x_{4}\right) \\
\quad+a_{12}\left(U_{\text {cell }}^{3}-U_{\text {cell }}^{4}\right), \\
c_{2} a_{12}\left(2 a_{9} x_{4}-a_{8} x_{3}-a_{10} x_{5}\right) \\
\quad+a_{12}\left(U_{\text {cell }}^{4}-U_{\text {cell }}^{5}\right), & y=x_{4}-x_{2}-x_{3}
\end{array} \\
& \quad y=x_{5}-x_{4}
\end{aligned}
$$

Due to all the $L_{\mathrm{g}}{ }^{1} h \neq 0$, the first derivative of the output variable $\boldsymbol{y}$ has a direct relationship with the control input $\boldsymbol{u}$. Thus, the control law can be described as

$$
\boldsymbol{u}=\frac{1}{L_{g}{ }^{1} h}\left(v-L_{f}{ }^{1} h-L_{\hat{d}}{ }^{1} h \Delta j\right)
$$

here, we define a track error $e=y_{\mathrm{d}}-y$, where $y_{d}$ is the desired value of the maximum temperature gradient. However, in a nonlinear dynamic system, even though it can be accurately linearized, tracking errors may exist as the parameters change, especially in the case where the load changes. Therefore, to eliminate the error, a new control input of the following form is introduced

$$
v=\dot{y}_{d}-k_{1} e-k_{2} \dot{e}
$$

where $v$ is the first-time derivative of $y$, that is, $\dot{y}=v$; then, we have

$$
\dot{e}-k_{1} e-k_{2} \dot{e}=0
$$

By tuning the parameters $k_{1}$ and $k_{2}$, the characteristic polynomial of 32 is the Hurwitz polynomial; this means that the tracking error $e$ converges to zero and the established controller is effective. ${ }^{28}$

\section{RESULTS AND DISCUSSION}

In the MATLAB/Simulink environment, the validation of the SOFC dynamic model is first verified. Then, the input-output feedback linear control strategy is simulated and the

\begin{tabular}{|c|c|c|}
\hline symbol & definition & value (unit) \\
\hline$c_{p}^{\text {an }}$ & anode specific heat capacity & $27.3032 \mathrm{~J} \cdot \mathrm{mol}^{-1} \cdot \mathrm{K}^{-1}$ \\
\hline$c_{p}^{p}$ & cathode specific heat capacity & $35.0058 \mathrm{~J} \cdot \mathrm{mol}^{-1} \cdot \mathrm{K}^{-1}$ \\
\hline$\rho_{\mathrm{mol}}^{\text {an }}$ & anode molar density & $32222 \mathrm{~mol} \cdot \mathrm{m}^{-3}$ \\
\hline$\rho_{\mathrm{mol}}^{\mathrm{ca}}$ & cathode molar density & $22839 \mathrm{~mol} \cdot \mathrm{m}^{-3}$ \\
\hline$V_{\text {gas }}^{\text {an }}$ & anode channel volume & $1.62 \times 10^{-6} \mathrm{~m}^{3}$ \\
\hline$V_{\text {gas }}^{\mathrm{ca}}$ & cathode channel volume & $3.24 \times 10^{-6} \mathrm{~m}^{3}$ \\
\hline$I_{\mathrm{L}}^{\circ}$ & limit current & $100 \mathrm{~A}$ \\
\hline$I_{0}$ & exchange current & $80 \mathrm{~A}$ \\
\hline$R_{\mathrm{ohm}}$ & ohm resistance & $200 \Omega$ \\
\hline$y_{\mathrm{H}_{2}}^{\text {in }}$ & the initial mole fraction of hydrogen & 0.97 \\
\hline$y_{\mathrm{H}_{2} \mathrm{O}}$ in & the initial mole fraction of water vapor & 0.03 \\
\hline$y_{\mathrm{O}_{2}}{ }^{\text {in }}$ & the initial mole fraction of oxygen & 0.21 \\
\hline$F$ & Faraday constant & $96485 \mathrm{C} \cdot \mathrm{m} \mathrm{ol}^{-1}$ \\
\hline$R$ & ideal gas constant & $8.3142 \mathrm{~J} \cdot \mathrm{mol}^{-1} \cdot \mathrm{K}^{-1}$ \\
\hline$T_{\text {in }}$ & input fuel temperature & $1000 \mathrm{~K}$ \\
\hline$N$ & number of cells & 20 \\
\hline
\end{tabular}
corresponding temperature gradient control results are described in this section.

5.1. Model Verification. In this paper, we choose the cathode input air flow and the anode input fuel flow as the model inputs, and the five nodes' temperatures of the SOFC as the outputs. The parameter setting values used in eqs $1-17$ are given in Table 1. The initial conditions are given as follows: the

\section{Table 1. Modeling Parameters of the SOFC}

input fuel temperature is $T_{\text {in }}=1000 \mathrm{~K}$, the initial temperature of the air in the cathode flow channel is $1060 \mathrm{~K}$, the cathode input air flow rate is $F_{\mathrm{ca}}^{\text {in }}=2.742 \times 10^{-3} \mathrm{~mol} \cdot \mathrm{s}^{-1},{ }^{21}$ and the current value is set as $2 \mathrm{~A}$. To ensure uniform distribution of the temperature and the voltage inside the SOFC, the fuel utilization is chosen as $u_{\mathrm{f}}=0.85^{30}$

During the normal operation of the SOFC, a load disturbance causes the stack current to have a step change (from $2 \mathrm{~A}$ to $3 \mathrm{~A}$ ) at $t=500 \mathrm{~s}$. In this situation, the five nodes' temperature dynamic characteristic curves and maximum temperature gradient response graphic are depicted as Figure 3. According to the temperature distribution, the node temperatures have a smooth increase when there is a step increase in the current. This is because the load current increasing will cause more intensive electrochemical reaction. Thus, it will release more heat and gradually increase the stack temperature in each node. As the temperature changes, the maximum temperature gradient also changes. It can be seen from Figure 3a that the temperature of the five nodes satisfies $T_{\text {sol }}^{1}<T_{\text {sol }}^{2}<T_{\text {sol }}^{3}<T_{\text {sol }}^{4}<T_{\text {sol. }}^{5}$. Furthermore, the maximum temperature gradient of the increasing trend can be seen in Figure $3 b$, which is the same as the objective situation. These descriptions indicate that the dynamic model presented in this 


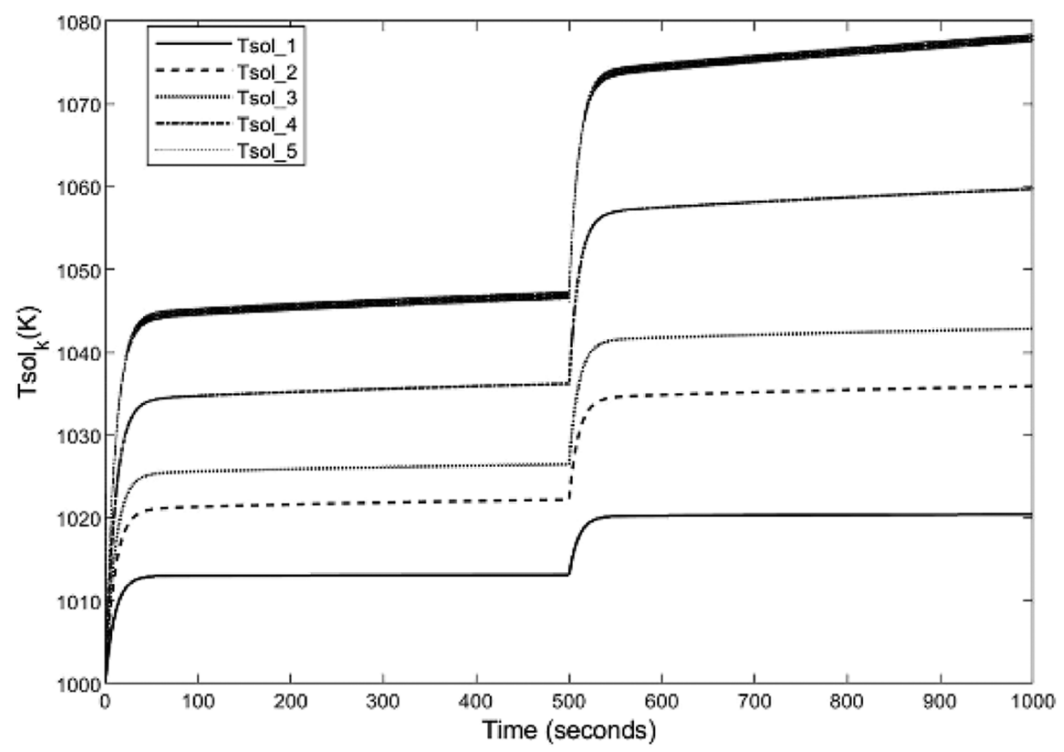

(a)

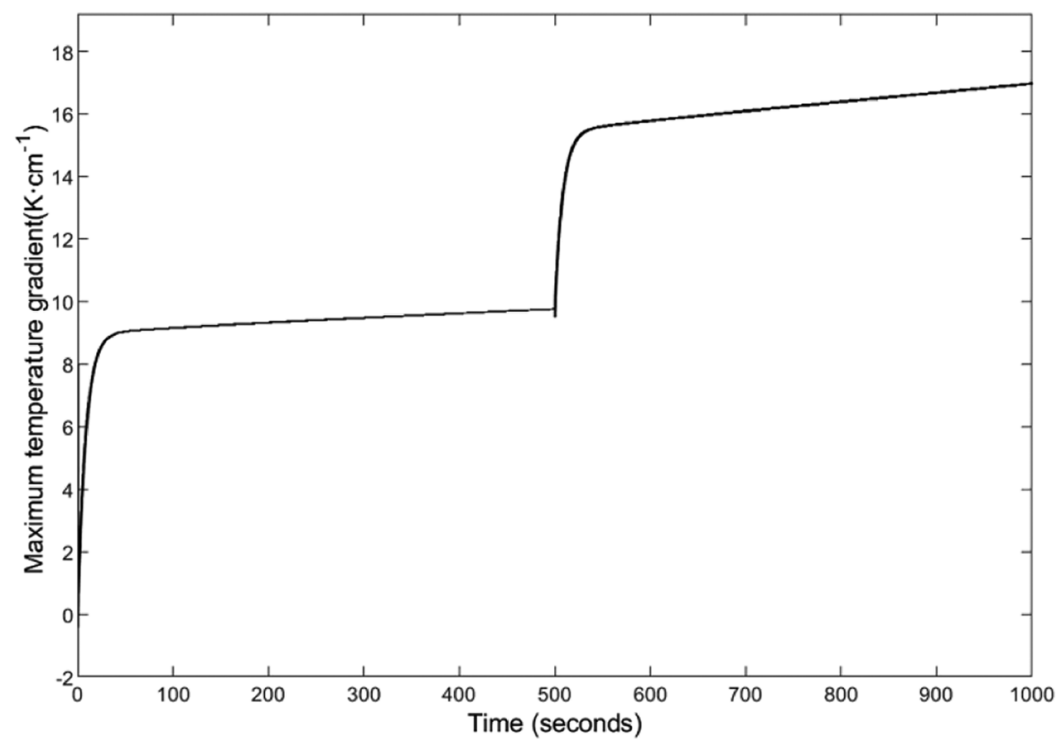

(b)

Figure 3. Simulation diagram of the temperature dynamic characteristics. (a) Five-node temperature dynamic response curve. (b) Maximum temperature gradient dynamic response curve.

paper can be applied to accurately describe the dynamic characteristics of the SOFC.

5.2. Temperature Gradient Control. In general, as the load current increases, the SOFC stack temperature rises because the molar concentration of reactants along the direction of the gas flow gradually decreases. Due to larger cathode input air flow and the specific heat capacity of the air is higher than that of the fuel, the stack temperature gradient can be reduced by increasing the cathode input air flow. In this study, the maximum temperature gradient within the anode fuel flow channel of the SOFC is controlled by adjusting the cathode input air flow.

To access the control performance of the proposed control strategy, we choose the current disturbance as a multiple-step signal which increases from 2 to $3 \mathrm{~A}$ at $500 \mathrm{~s}$ and goes on to
3.5 A after $1000 \mathrm{~s}$. The current change curve is shown in Figure 4. Based on the control-oriented model of the SOFC, the input-output feedback linearization control strategy can be developed. In this study, the control objective is to maintain the maximum temperature gradient of the SOFC as the desired value $\left(T_{\mathrm{sol}, \mathrm{g}, \mathrm{mef}}^{\mathrm{max}}=8 \mathrm{~K} \cdot \mathrm{cm}^{-1}\right)$ by adjusting the cathode input air flow. Using the input-output feedback linearization control strategy, combining pole placement technique, where the parameters are tuned as $k_{1}=25$ and $k_{2}=1.25$, the presented temperature gradient control scheme is simulated and the result is described by a solid line. For the purpose of comparison, the compound control law proposed in ref 13 is also used to control the maximum temperature gradient and the response is depicted by a dashed line; their comparison results are shown in Figure 5. 


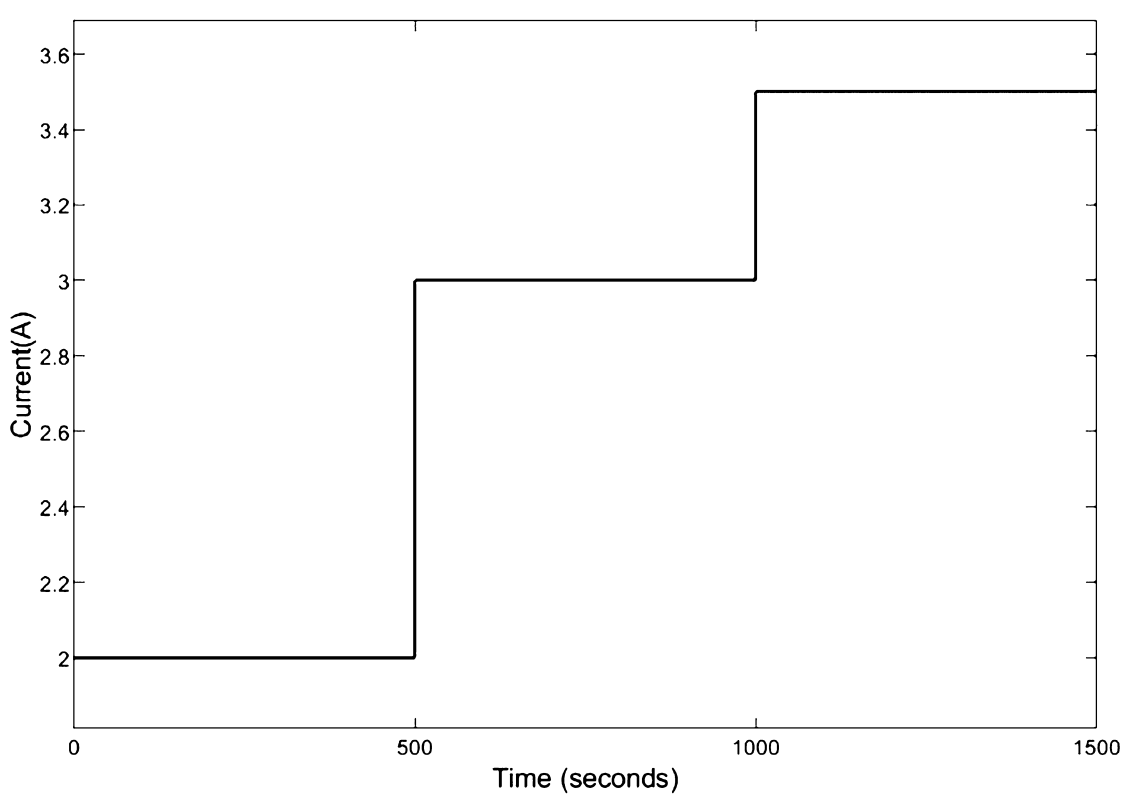

Figure 4. Step curve of current.

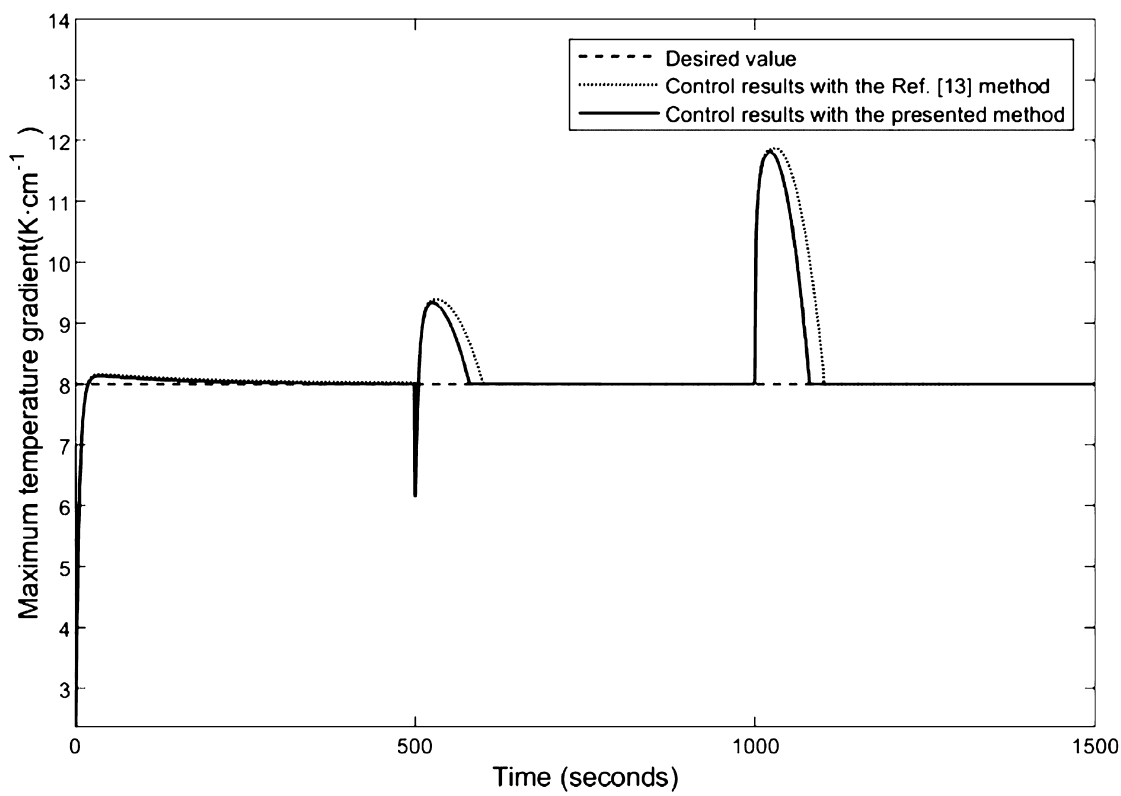

Figure 5. Maximum temperature gradient control results of the SOFC using the presented controller and the method in ref 13 .

From Figure 5, one will notice that both the above controllers can ensure the maximum temperature gradient of the SOFC to the desired value accurately. In the case of the above disturbances, it is worth to note that the maximum temperature gradient response rate for the control method in the ref 13 is much slower than that for the presented controller under the same control objective. This clearly proves the favorable performance of the presented controller for the maximum temperature gradient control of the SOFC.

To eliminate the real-time error between the actual and the desired maximum temperature gradient, the control input (the cathode input air flow) is given as Figure 6. As can be seen from Figure 6, when the current increases, the maximum temperature gradient of the SOFC can stabilize at the desired value by increasing the cathode input air flow.

\section{CONCLUSIONS}

The main task of this study is to control the maximum temperature gradient at its desired value in the presence of the load current. To satisfy the variable requirements of the control strategy, a control-oriented temperature-gradient nonlinear dynamic model of the SOFC is first established. Simulations show the feasibility of the established model, which can accurately reflect the steady state and transient operation of the temperature at each node.

Then, an input-output feedback linearization controller for the maximum temperature gradient control is proposed to make the control objective come true. The result shows that the proposed controller has the better control performance by comparing with the compound controller. Although the maximum temperature gradient can reach the same steadystate value under both control laws, the presented controller 


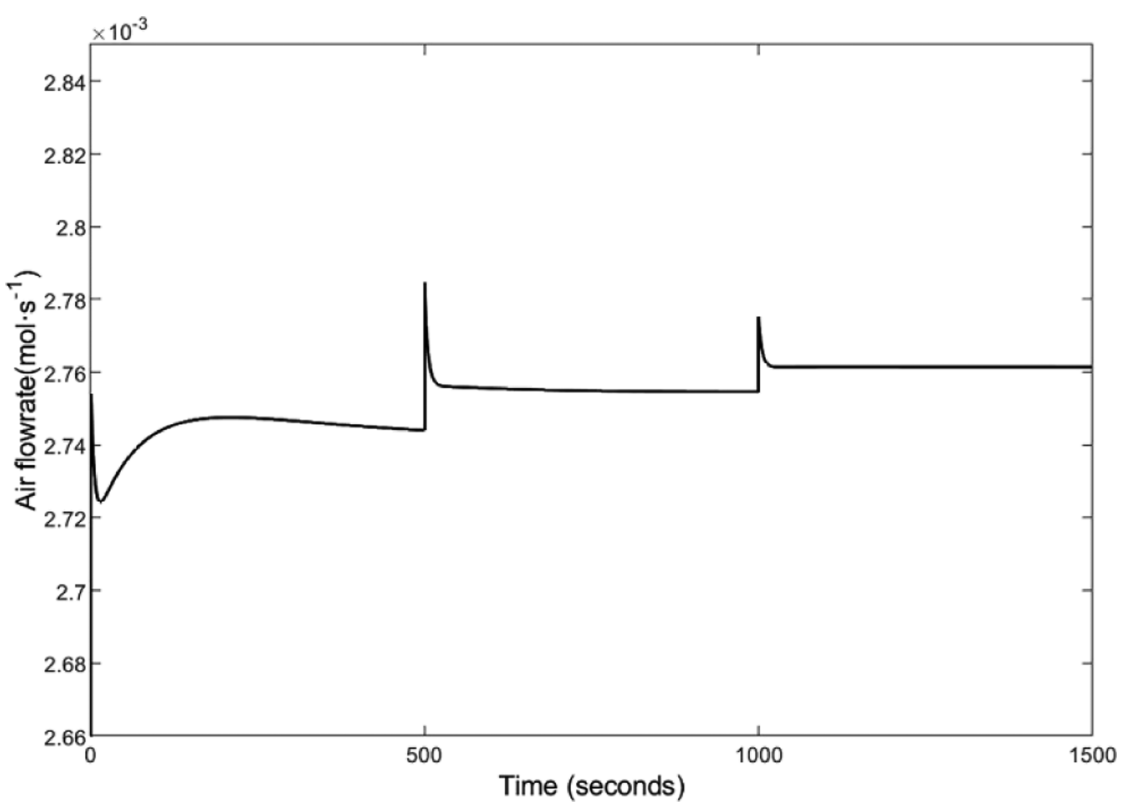

Figure 6. Curve of the control input (the cathode input air flow).

possesses the characteristics of faster response time and higher control precision.

As the future work. we ought to focus on the dynamic characteristics of the air temperature and its effect on the temperature gradient of the solid structure of the SOFC, rather than simply assuming that the temperatures of the fuel and the solid structure are the same. Furthermore, applying the presented temperature gradient controller to a more complicated and truer SOFC system proves the theoretical feasibility.

\section{ASSOCIATED CONTENT}

\section{(s) Supporting Information}

The Supporting Information is available free of charge at https://pubs.acs.org/doi/10.1021/acsomega.1c01359.

Calculation equations of each data in Table 1 and its corresponding initial data (PDF)

\section{AUTHOR INFORMATION}

\section{Corresponding Authors}

Haibo Huo - College of Engineering Science and Technology, Shanghai Ocean University, Shanghai 201306, China;

Email: hbhuo@shou.edu.cn

Xinghong Kuang - College of Engineering Science and Technology, Shanghai Ocean University, Shanghai 201306, China; Email: xhkuang@shou.edu.cn

\section{Authors}

Kui Xu - College of Engineering Science and Technology, Shanghai Ocean University, Shanghai 201306, China; (1) orcid.org/0000-0003-0265-6938

Lixiang Cui - College of Engineering Science and Technology, Shanghai Ocean University, Shanghai 201306, China

Hao Zhang - College of Engineering Science and Technology, Shanghai Ocean University, Shanghai 201306, China

Jingxiang Xu - College of Engineering Science and Technology, Shanghai Ocean University, Shanghai 201306, China; (1) orcid.org/0000-0002-1484-9692

Complete contact information is available at: https://pubs.acs.org/10.1021/acsomega.1c01359

\section{Notes}

The authors declare no competing financial interest.

\section{ACKNOWLEDGMENTS}

This work was supported by the Young Eastern Scholar Program at Shanghai Institutions of Higher Learning, Special funding for the development of science and technology of Shanghai Ocean University (grant no. A2-2006-00-200211), and the Shanghai Pujiang Program (grant no. 18PJ1404200).

\section{NOMENCLATURE}

F, mole flow rate $\left(\mathrm{mol} \cdot \mathrm{s}^{-1}\right)$ or Faraday's constants, (96485 C. $\left.\mathrm{mol}^{-1}\right) ; V$, volume $\left(\mathrm{m}^{3}\right) ; y$, mole fraction; $r$, reaction rate term; $I$, stack current $(A) ; I_{0}$, change current $(A) ; I_{L}$, limited current $(A) ; N$, numbers of cells in the stack; $R$, universal gas constant $\left(8.314 \mathrm{~J} \cdot \mathrm{mol}^{-1} \cdot \mathrm{K}^{-1}\right) ; R_{\mathrm{ohm}}$, ohmic resistance $(\Omega) ; c_{\mathrm{p}}$, specific heat capacity $\left(\mathrm{J} \cdot \mathrm{mol}^{-1} \cdot \mathrm{K}^{-1}\right) ; u_{\mathrm{f}}$, fuel utilization; $T$, temperature $(K) ; U$, voltage $(V) ; E_{\mathrm{N}}$, open-circuit voltage $(V)$

\section{REFERENCES}

(1) Stambouli, A. B.; Traversa, E. Solid oxide fuel cells (SOFCs): a review of an environmentally clean and efficient source of energy. Renew. Sustain. Energy Rev. 2002, 6, 433-455.

(2) İskenderoğlu, F. C.; Baltacioğlu, M. K.; Demir, M. H.; Baldinelli, A.; Barelli, L.; Bidini, G. Comparison of support vector regression and random forest algorithms for estimating the SOFC output voltage by considering hydrogen flow rates. Int. J. Hydrogen Energy 2020, 45, 35023-35038.

(3) Cheng, H.; Li, X.; Jiang, J.; Deng, Z.; Yang, J.; Li, J. A nonlinear sliding mode observer for the estimation of temperature distribution in a planar solid oxide fuel cell. Int. J. Hydrogen Energy 2015, 40, 593606.

(4) Zhang, L.; Jiang, J.; Cheng, H.; Deng, Z.; Li, X. Control strategy for power management, efficiency-optimization and operating-safety of a $5-\mathrm{kW}$ solid oxide fuel cell system. Electrochim. Acta 2015, 177, 237-249.

(5) Ahmed, A.; Shahid Ullah, M.; Ashraful Hoque, M. Optimal Design of Proportional-Integral Controllers for Grid-Connected Solid 
Oxide Fuel Cell Power Plant Employing Differential Evolution Algorithm. IJST-T Electr. Eng. 2019, 43, 999-1019.

(6) El-Hay, E. A.; El-Hameed, M. A.; El-Fergany, A. A. Optimized Parameters of SOFC for steady state and transient simulations using interior search algorithm. Energy 2019, 166, 451-461.

(7) Botta, G.; Romeo, M.; Fernandes, A.; Trabucchi, S.; Aravind, P. V. Dynamic modeling of reversible solid oxide cell stack and control strategy Development. Energy Convers. Manag. 2019, 185, 636-653.

(8) Xia, Y.; Zou, J.; Yan, W.; Li, H. Adaptive Tracking Constrained Controller Design for Solid Oxide Fuel Cells Based on a Wiener-Type Neural Network. Appl. Sci. 2018, 8, 1-18.

(9) Eawryńczuk, M. Constrained computationally efficient nonlinear predictive control of Solid Oxide Fuel Cell: Tuning, feasibility and performance. ISA Trans. 2020, 99, 270-289.

(10) Yu, S.; Fernando, T.; Chau, T. K.; Iu, H. H.-C. Voltage Control Strategies for Solid Oxide Fuel Cell Energy System Connected to Complex Power Grids Using Dynamic State Estimation and STATCOM. IEEE Trans. Power Syst. 2017, 32, 3136-3145.

(11) Kulikovsky, A. A. A simple equation for temperature gradient in a planar SOFC stack. Int. J. Hydrogen Energy 2010, 35, 308-312.

(12) Zeng, Z.; Qian, Y.; Zhang, Y.; Hao, C.; Dan, D.; Zhuge, W. A review of heat transfer and thermal management methods for temperature gradient reduction in solid oxide fuel cell (SOFC) stacks. Appl. Energy 2020, 280, 1-19.

(13) Wu, X.; Yang, D.; Wang, J.; Li, X. Temperature gradient control of a solid oxide fuel cell stack. J. Power Sources 2019, 414, 345-353.

(14) Ahmed, A.; Ullah, M. S. Input-Output Linearization-Based Controller Design for Stand-Alone Solid Oxide Fuel Cell Power Plant. Arabian J. Sci. Eng. 2016, 41, 3543-3558.

(15) Shirvani Boroujeni, M.; Markadeh, G. R. A.; Soltani, J. Torque ripple reduction of brushless DC motor based on adaptive inputoutput feedback linearization. ISA Trans. 2017, 70, 502-511.

(16) Yazdanpanah, R.; Soltani, J.; Arab Markadeh, G. R. Nonlinear torque and stator flux controller for induction motor drive based on adaptive input-output feedback linearization and sliding mode control. Energy Convers. Manag. 2008, 49, 541-550.

(17) Pipino, H. A.; Morato, M. M.; Bernardi, E.; Adam, E. J.; Normey-Rico, J. E. Nonlinear temperature regulation of solar collectors with a fast adaptive polytopic LPV MPC formulation. Sol. Energy 2020, 209, 214-225.

(18) Roca, L.; Guzman, J. L.; Normey-Rico, J. E.; Berenguel, M.; Yebra, L. Robust constrained predictive feedback linearization controller in a solar desalination plant collector field. Contr. Eng. Pract. 2009, 17, 1076-1088.

(19) Nechak, L. Nonlinear control of friction-induced limit cycle oscillations via feedback linearization. Mech. Syst. Signal Process. 2019, 126, 264-280.

(20) Jaypuria, S.; Ranjan Mahapatra, T.; Jaypuria, O. Metaheuristic Tuned ANFIS Model for Input-Output Modeling of Friction Stir Welding. Mater. Today 2019, 18, 3922-3930.

(21) Vijay, P.; Tadé, M. O. An adaptive non-linear observer for the estimation of temperature distribution in the planar solid oxide fuel cell. J. Process Control 2013, 23, 429-443.

(22) Vijay, P.; Tadé, M. O.; Ahmed, K.; Utikar, R.; Pareek, V. Simultaneous estimation of states and inputs in a planar solid oxide fuel cell using nonlinear adaptive observer design. J. Power Sources 2014, 248, 1218-1233.

(23) Luo, H.; Yin, Q.; Wu, G. P.; Li, X. A Nonlinear Luenberger Observer for the Estimation of Temperature Distribution in a Planar Solid Oxide Fuel Cell. Chinese Automation Congress, 2015, pp $1246-1251$.

(24) Wu, X.; Jiang, J.; Li, X.; Li, J. Modeling and Temperature Distribution Estimation Based on Kalman Filter Algorithm of a Planar Solid Oxide Fuel Cell. Chinese Automation Congress, 2017, pp 4281-4285.

(25) Sargado, J. M.; Keilegavlen, E.; Berre, I.; Nordbotten, J. M. A combined finite element-finite volume framework for phase-field fracture. Comput. Methods Appl. Mech. Eng. 2021, 373, 1-23.
(26) Huo, H.-B.; Wu, Y.-X.; Liu, Y.-Q.; Gan, S.-H.; Kuang, X.-H. Control-Oriented Nonlinear Modeling and Temperature Control for Solid Oxide Fuel Cell. J. Fuel Cell Sci. Technol. 2010, 7, 041005-1041005-9.

(27) Kumar, A. A.; Antoine, J.-F.; Abba, G. Input-Output Feedback Linearization for the Control of a 4 Cable-Driven Parallel Robot. IFAC PapersOnLine 2019, 52, 707-712.

(28) Lalili, D.; Mellit, A.; Lourci, N.; Medjahed, B.; Berkouk, E. M. Input output feedback linearization control and variable step size MPPT algorithm of a grid-connected photovoltaic inverter. Renew. Energy 2011, 36, 3282-3291.

(29) Djilali, L.; Sanchez, E. N.; Belkheiri, M. Neural Input Output Feedback Linearization Control of a DFIG based Wind Turbine. IFAC PapersOnLine 2017, 50, 11082-11087.

(30) Kandepu, R.; Imsland, L.; Foss, B. A.; Stiller, C.; Thorud, B.; Bolland, O. Modeling and control of a SOFC-GT-based autonomous power system. Energy 2007, 32, 406-417. 